\title{
Acute Lymphoblastic Leukemia: Fourteen Years Experience of a Single Institution
}

\author{
Sah KP ${ }^{1}$, Shrestha $\mathbf{P N}^{2}$
}

\begin{abstract}
Introduction: Leukemia commonly known as blood cancer is the most common malignant neoplasm in childhood accounting for about $41 \%$ of all malignancies that occur in children younger than 15 year of age. The objectives of this study were to find out the clinico-laboratory features and survival of children with acute lymphoblastic leukemia (ALL) during fourteen years in pediatric oncology unit of a tertiary care hospital. Materials and Methods: This was a retrospective study conducted at Kanti Children's Hospital (KCH) from March 1998 to March 2012. Bone marrow aspiration showing $\geq 25 \%$ blast cells was the criteria for diagnosis of ALL. Results: Out of 755 childhood cancers reported in this hospital during study period, total number of Acute leukemia patients were 375 (49.7\%). Among acute leukemia, patients with ALL were 300 , which was $80.0 \%$ among all leukemias and $39.7 \%$ of all cases of cancers. Among cases of ALL, L1, L2 and L3 constituted 163 (54.3\%), 131 (43.7\%) and 6 (2\%) respectively. The age of the children with acute leukemia ranged from six months to fourteen years, with a mean age of 7.3 years. The majority of children $(61.7 \%)$ with ALL fell into the age group of 2-9 years. Males: Female ratio was ( $\mathrm{M}: \mathrm{F}=1.3: 1$ ). The most common presenting features in ALL were fever (89.2 $\%)$, followed by splenomegaly (89.1\%), hepatomegaly $(69.2 \%)$ and lymphadenopathy (58.4\%). Among all patients, remission rate was $28.3 \%$ at $\geq 5$ years, $17.7 \%$ were on maintenance, $30.3 \%$ abandoned treatment and $23.7 \%$ died. Conclusion: This study showed that the patients on remission at $\geq 5$ years in this centre were $28.3 \%$.
\end{abstract}

Key words: ALL, Leukemia, Five year survival, Remission

\section{Introduction}

eukemia, commonly known as blood cancer, is the most common Lmalignant neoplasm in childhood accounting for about $41 \%$ of all malignancies that occur in children younger than 15 year of age $^{1}$. It is defined as a group of malignant diseases in which genetic abnormalities in the hematopoietic system give rise to a clonal proliferation of cells ${ }^{1}$. The progeny of these cells have a growth advantage over normal cellular elements owing to an increased rate of proliferation, a decreased rate of spontaneous apoptosis, or both. The result is a disruption of normal marrow function and ultimately, marrow failure ${ }^{1}$.
'Dr. Kailash Prasad Sah, MBBS, DCH, MD, Assistant Professor and Consultant Paediatric Oncologist. ${ }^{2}$ Dr. Pun Narayan Shrestha, MBBS, MD, Assistant Professor. Both from the Oncology Unit of Kanti Children's Hospital, Maharajgunj, Kathmandu, Nepal.

\section{Address for correspondence}

Dr. Kailash Prasad Sah

Assistant Professor and Consultant Paediatric Oncologist

Oncology Unit, Kanti Children's Hospital, Maharajgunj, Kathmandu, Nepal.

Tel: +977-9841265963

E-mail: sahkailash@hotmail.com

\section{How to cite}

Sah KP, Shrestha PN. Acute Lymphoblastic Leukemia: Fourteen Years Experience of a Single Institution. J Nepal Paediatr Soc 2014;34(1):1-6.

doi: http://dx.doi.org/10.3126/jnps.v34i1.9056

This work is licensed under a Creative Commons Attribution 3.0 License.

(c) (i)

Before the Second World War hematological malignancies were incurable. The best that could be done in those years was to establish the diagnosis. The first possibility of cure for childhood acute lymphoblastic leukemia (ALL) came in the 1950's with the introduction of agents capable of inducing remission ${ }^{2}$. Now a days, with the development in medical sciences, these diseases have become largely curable. In the last four decades, for instance, the cure rate of ALL and Hodgkin's lymphoma has increased from $0 \%$ to $75 \%$ and $90 \%$ respectively. 
A paper published by Afiqul Islam and Tim Eden from a center in Bangladesh has reported that the overall cure rate of pediatric cancer to be $50-60 \%$. The patients who discontinued treatment was $43 \% .^{3}$. A single center patient registry from South India by Kamalakshi Bhat et.al. reports 103 cases of ALL in 10 years. ${ }^{4}$

In Nepal, due to lack of proper cancer registry, nationwide incidence of cancers is not available. But a hospital based study done by Karmacharya $\mathrm{LL}$ et $\mathrm{al}^{5}$ with the cases registered at Kanti Children Hospital from 1997 to 2003 AD reported 129 (40\%) cases of Acute Lymphoblastic Leukemia, out of 323 admissions.

\section{Materials and Methods}

This was a retrospective study conducted in the oncology unit of Kanti Children's hospital, Kathmandu $(\mathrm{KCH}) . \mathrm{KCH}$ is 500 bedded tertiary level government hospital and the oncology unit has 20 indoor beds, 8 daycare beds, and outpatient clinics. It has almost $100 \%$ bed occupancy throughout the year.

All confirmed cases of ALL (defined as Bone marrow aspiration showing $\geq 25 \%$ blast cells) ${ }^{6}$ in children up to 14 years of age attending $\mathrm{KCH}$ from March 1998 to March 2012 were included in the study. Patients coming with relapse were excluded.

Data was collected from hospital records and following clinical parameters were noted: age, sex, presence or absence of - fever, joint and bone pain, pallor, abdominal swelling, skin rash, bleeding, parotid swelling, hepatomegaly, splenomegaly, lymphadenopathy, petechiae \& ecchymoses. Initial laboratory parameters like Blood group, Hemoglobin (Hb), Total Leucocylte Count (TLC), Total platelet count, blast cells in peripheral blood film were also noted.

Standard British protocol- MRC 2002 was used to treat according to the risk stratification category (standard and high risk). Standard risk patients are children with age between 1 to 9 years and TLC $<50000 / \mathrm{cc}$ at diagnosis. High risk are children with age $<1$ yr or $>10 y r$ or TLC $>50,000 / c c$ at diagnosis, $t(9 ; 22)$ Philadelphia chromosome positive, CNS or mediastinal mass involvement, T-cell marker CD3,5,7 positive ${ }^{6,7}$. Protocols consist of induction, CNS prophylaxis, consolidation and maintenance phase.

Children were followed up every week with peripheral blood smear. Bone marrow aspiration was done once after the induction phase and then yearly. Child was considered to be in remission if peripheral blood smear didn't show any blast cells and bone marrow showed less than $5 \%$ of blast cells.

Clinico laboratory features at the time of diagnosis, $\geq 5$ years remission, treatment abandoned and mortality were noted and analysed.

\section{Results}

Out of 755 childhood cancers reported in this hospital during study period, total number of Acute leukemia patients were 375 (49.7\%). Among acute leukemia, patients with ALL were 300, which was $80.0 \%$ among all leukemias and $39.7 \%$ of all cases of cancers. Among cases of ALL, L1, L2 and L3 constituted 163 (54.3\%), 131 (43.7\%) and 6 (2\%) respectively.

The age of children ranged from 6 months to 14 years with a mean age of 7.3 years. The majority of children (61.7\%) with ALL fell into the age group of 2-9 years. There were 171 (57.0\%) males and 129 (43.0 $\%)$ females with the male to female ratio of 1.3:1. The most common subtype according to $\mathrm{FAB}$ classification was L1 (54.3\%) followed by L2 (43.7\%). The most common presenting features of ALL were fever (92.3\%) followed by splenomegaly (88.0\%), hepatomegaly $(69.2 \%)$, lymphadenopathy (58.4\%) and echymosis (20.0\%).

ALL was found most commonly in patients with blood group $B+$ ve (39.7\%) followed by $A+$ ve $(28.3 \%)$. Total initial WBC count were $<50,000$ in more than two third of the cases whereas $11.3 \%$ had initial WBC count $>50,000$. More than two third (78.3\%) of the cases had blast cells in peripheral blood smear whereas $6.7 \%$ showed atypical cells. 15\% didn't have any blast cells in peripheral smear. $75 \%$ of the cases had their initial platelets count $<50,000 /$ cu.mm.

Remission rate at $\geq 5$ years among ALL cases in this centre was $28.3 \%$. 53 cases (17.7\%) are still on maintenance chemotherapy, 91 (30.3\%) had abandoned treatment due to financial burden and 72 (23.7\%) died. 
Table 1: Age and sex distribution of ALL $(n=300)$

\begin{tabular}{|c|c|c|c|c|c|c|}
\hline \multirow{3}{*}{ Age (in yrs) } & \multicolumn{6}{|c|}{ ALL } \\
\hline & \multicolumn{2}{|c|}{ Male } & \multicolumn{2}{|c|}{ Female } & \multicolumn{2}{|c|}{ Total } \\
\hline & No & $\%$ & No & $\%$ & No & $\%$ \\
\hline$<2$ & 19 & 11.3 & 14 & 10.6 & 33 & 11 \\
\hline $2-5$ & 81 & 48.2 & 70 & 53.03 & 151 & 50.3 \\
\hline$>5-9$ & 38 & 22.6 & 29 & 21.9 & 67 & 22.3 \\
\hline.$>9$ & 30 & 17.8 & 19 & 14.3 & 49 & 16.3 \\
\hline Total & 168 & 56 & 132 & 44 & 300 & 100 \\
\hline
\end{tabular}

Table 2: Distribution of ALL cases by FAB classification $(n=300)$

\begin{tabular}{|c|c|c|c|}
\hline & Male & Female & Total \\
\hline $\mathrm{L}_{1}$ & 90 & 73 & $163(54.3)$ \\
\hline $\mathrm{L}_{2}$ & 77 & 54 & $131(43.7)$ \\
\hline $\mathrm{L} 3$ & 4 & 2 & $6(2.0)$ \\
\hline Total & $\mathbf{1 7 1} \mathbf{5 7 . 0} \%)$ & $\mathbf{1 2 9}(\mathbf{4 3 . 0} \%)$ & $\mathbf{3 0 0}$ \\
\hline
\end{tabular}

Table 3: Symptoms of ALL $(n=300)$

\begin{tabular}{|l|c|c|}
\hline Presenting features & Number of cases & Percentage \\
\hline Fever & 277 & 92.3 \\
\hline Pallor & 165 & 55.0 \\
\hline Joint \& bone pain & 115 & 38.4 \\
\hline Abdominal swelling & 106 & 35.3 \\
\hline Skin rash & 73 & 24.3 \\
\hline Bleeding & 6 & 2.0 \\
\hline Parotid swelling & 5 & 1.7 \\
\hline
\end{tabular}

*One child could be having more than one feature

Table 4: Signs of ALL $(n=300)$

\begin{tabular}{|l|c|c|}
\hline \multicolumn{1}{|c|}{ Presenting features } & $\begin{array}{c}\text { Number of } \\
\text { cases }\end{array}$ & Percentage \\
\hline Fever & 277 & 92.3 \\
\hline Splenomegaly & 264 & 88.0 \\
\hline Lymphadenopathy & 215 & 71.6 \\
\hline Hepatomegaly & 210 & 70.0 \\
\hline Petechial \& Echymosis & 106 & 35.3 \\
\hline Sternal tenderness & 10 & 3.3 \\
\hline Respiratory added sounds & 5 & 1.6 \\
\hline Pedal oedema & 2 & 0.66 \\
\hline
\end{tabular}

* One child could be having more than one feature

Table 5: Blood grouping in ALL $(n=300)$

\begin{tabular}{|c|c|c|}
\hline Blood group & Number & Percentage \\
\hline $\mathrm{B}+$ & 119 & $39.7 \%$ \\
\hline $\mathrm{A}+$ & 85 & $28.3 \%$ \\
\hline $\mathrm{O}+$ & 73 & $24.3 \%$ \\
\hline $\mathrm{AB}+$ & 9 & $3 \%$ \\
\hline $\mathrm{A}-$ & 8 & $2.7 \%$ \\
\hline $\mathrm{O}-$ & 6 & $2 \%$ \\
\hline Total & $\mathbf{3 0 0}$ & $\mathbf{1 0 0} \%$ \\
\hline
\end{tabular}

Table 6: WBC Count in ALL $(n=300)$

\begin{tabular}{|c|c|c|}
\hline Leucocyte count & Number & Percentage \\
\hline$<10000$ & 145 & $48.3 \%$ \\
\hline $10000-50000$ & 120 & $40 \%$ \\
\hline$>50000$ & 35 & $11.7 \%$ \\
\hline Total & 300 & $100 \%$ \\
\hline
\end{tabular}

Table 7: Peripheral blasts in ALL $(n=300)$

\begin{tabular}{|c|c|c|}
\hline Peripheral blasts & Number & Percentage \\
\hline Present & 235 & 78.3 \\
\hline Not present & 45 & 15 \\
\hline Atypical cells & 20 & 6.7 \\
\hline Total & $\mathbf{3 0 0}$ & $\mathbf{1 0 0}$ \\
\hline
\end{tabular}

Table 8: Hb level in ALL $(n=300)$

\begin{tabular}{|c|c|c|}
\hline Hb (grams \%) & No of cases & Percentage \\
\hline$<7$ & 45 & 15 \\
\hline $7-11$ & 255 & 85 \\
\hline Total & $\mathbf{3 0 0}$ & $\mathbf{1 0 0}$ \\
\hline
\end{tabular}

Table 9: Platelets counts in ALL $(n=300)$

\begin{tabular}{|c|c|c|}
\hline Platelet count $(\mathbf{c m m})$ & No of cases & Percentage \\
\hline$<20,000$ & 120 & 40 \\
\hline $20,000-50,000$ & 105 & 35 \\
\hline$>50,000$ & 75 & 25 \\
\hline Total & $\mathbf{3 0 0}$ & $\mathbf{1 0 0}$ \\
\hline
\end{tabular}

Table 10: Outcomes in ALL $(n=300)$

\begin{tabular}{|c|c|c|}
\hline Outcome & No of cases & Percentage \\
\hline $\begin{array}{c}\text { Event Free Survival ( }>5 \\
\text { years) }\end{array}$ & 84 & 28 \\
\hline $\begin{array}{c}\text { On maintenance } \\
\text { Chemotherapy }\end{array}$ & 53 & 17.7 \\
\hline Lost follow up & 91 & 30.3 \\
\hline Died & 72 & 24 \\
\hline Total & $\mathbf{3 0 0}$ & $\mathbf{1 0 0}$ \\
\hline
\end{tabular}




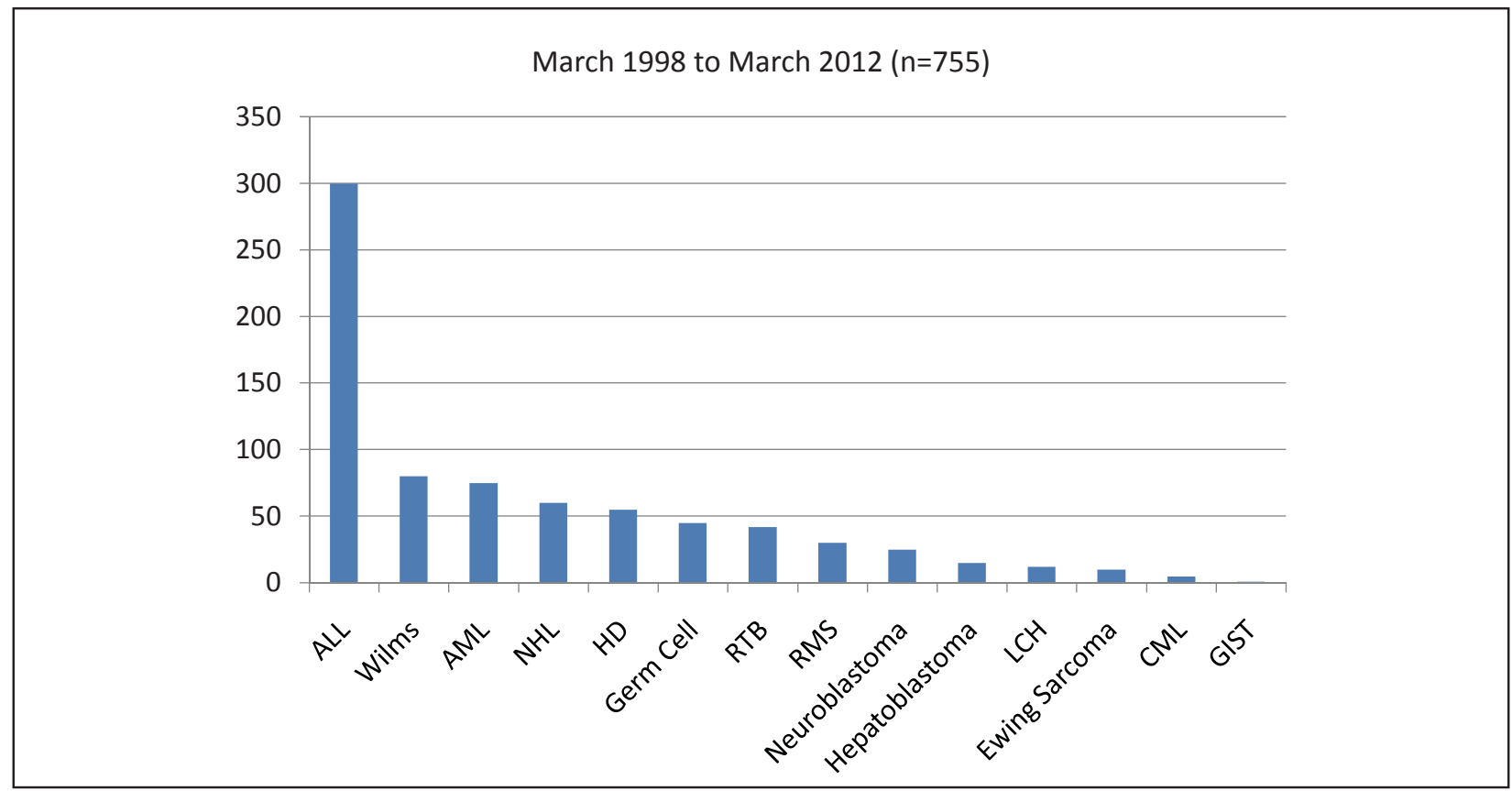

Fig 1: Distribution of cancer cases during fourteen years at $\mathrm{KCH}$.

(ALL - Acute lymphoblastic leukemia, AML - Acute myeloid leukemia, NHL - non-Hodgkin's lymphoma, HD - Hodgkin disease, RTB - Retinoblastoma, RMS - Rhabdomyosarcoma, LCH - Langerhans cell histiocytosis, CML - chronic myeloid leukemia, GIST Gastrintestinal stromal tumour

\section{Discussion}

The age of the children ranged from 6 months to 14 years, with a mean age of 7.3 years. The majority of children (50.3\%) with ALL fell into the age group of 2-5 years. This is the age group at standard risk.

In contrast to present study, the study conducted by Moula et al in Bangladesh found the most affected age group to be 2-4 $\mathrm{yrs}^{8}$. This is similar to that mentioned by Margolin JF, Steuber CP, Poplack DG ${ }^{6}$. It is also similar to that mentioned by Tubergen DG, Bleyer A and Ritchey AK ${ }^{9}$.

In this study male $(57.0 \%)$ children with ALL predominated females $(43.0 \%$ ) and the male to female ratio was found to be $1.3: 1$. This male to female ratio is exactly the same as observed by Makimbetov EK in a study in Kyrgyzstan ${ }^{10}$. D'Costa GG et al ${ }^{11}$ observed exactly similar male to female ratio in a study in India. The study conducted by Dabbous IA at Beirut Lebnon ${ }^{12}$ also observed similar male to female ratio of 1.7:1. However, this finding markedly differed from the study conducted in Bangladesh by Moula et al. ${ }^{8}$ who observed that the male to female ratio is $3.8: 1$. This discrepancy in male to female ratio could be due to the fact that boys in Bangladesh are given more medical attention than girls as mentioned by Moula et $\mathrm{al}^{8}$.
In our study ALL was found in $39.8 \%$ of the cases among all childhood cancers, which is slightly higher than the incidence as mentioned in the standard text book which mentions that ALL accounts for approximately one fourth of all childhood cancers ${ }^{13}$. Our study showed $80 \%$ of all acute leukemias cases are ALL. A study done by Dabbous I.A. at Beitut, Lebanon ${ }^{12}$ also showed that ALL was found in $73.5 \%$ of leukemia cases, which is coinciding with the finding of the study. Moula et al in a study in Bangladesh found similar incidence of ALL in children (78.49\% $)^{8}$.

Fever was the most common presenting feature in this study and was present in $92.8 \%$ of the patients followed by pallor (55\%). D'Costa GG et al. ${ }^{11}$ also found fever as the commonest feature followed by weakness bleeding and bone pain. Mannan MA et al. ${ }^{14}$ also observed fever to be the most common presenting feature in children with ALL. It was present in $68 \%$ of ALL patients.

Pallor was found to be the second most common presenting feature in this study and was present in $55.0 \%$ of cases with ALL. In contrast to present study it was found to be commonest feature by Moula ${ }^{8}$ in the study conducted in Bangladesh. Kapoor $G$ and Prabhash $\mathrm{K}^{15}$ in their study in India observed pallor as the most common presenting feature in children 
with ALL. Bony pain was found to be the third most common presenting feature of acute leukemia and ALL in this study and was present in $32.7 \%$ of cases with acute leukemia and $38.1 \%$ of ALL. Moula ${ }^{8}$ in their study conducted in Bangladesh observed bone pain as the seventh most common presenting feature in children with acute leukemia and was present in $17.2 \%$ of the patients. Margolin JF et $\mathrm{al}^{6}$ mentioned bone pain as the third common occurring symptom in children with ALL and were observed in $23 \%$ of the patients. D'Costa GG et $\mathrm{al}^{11}$ on other hand found bone pain as the fourth common feature in children with ALL in their study.

This study found lymphadenopathy in $71.6 \%$ of children with ALL. A study conducted in Bangladesh by Moula et al. ${ }^{8}$ observed this finding in $39.7 \%$ of children with acute leukemia. Kapoor $\mathrm{G}$ and Prabhash $\mathrm{K}^{15}$ in India observed lymphadenopathy in $86 \%$ of children with ALL which is higher than the finding of this study. Arya $\mathrm{LS}^{16}$ et al also found similar incidence (88\%) of lymphadenopathy in ALL. Still lower incidence (23.8\%) was noted in a study done by Baka $\mathrm{M}$ et $\mathrm{al}^{17}$ in Greece. Margolin JF et $\mathrm{al}^{6}$ mentioned that it is present in about $50 \%$ of children with ALL.

Different authors defined bleeding differently. Some defined it as the presence of petechiae or purpura, others as bleeding from nose or other sites. This could be the reason for discrepancy in the frequency of bleeding manifestations in children with leukemia. Bleeding from any site was found to be present in $7.3 \%$ of acute leukemia and $9.5 \%$ of ALL cases. D'Costa GG et $\mathrm{al}^{11}$ in a study done in India observed bleeding as third most common sign in children with acute leukemia. Moula QM et al $^{8}$ also found bleeding manifestation in $30.1 \%$ of children with acute leukemia, which is much more, frequent than my finding. Mannan MA et al ${ }^{14}$ in a study conducted in Bangladesh observed bleeding manifestation in $63 \%$ of ALL cases, which is almost seven times more frequent than the finding of our study.

Some of the studies have mentioned hepatomegaly and splenomegaly together as hepatosplenomegaly, however others mentioned it separately. Hepatomegaly and splenomegaly were separately studied in this study thus splenomegaly was observed in $90.2 \%$ and hepatomegaly in $70.0 \%$ of children with ALL. Moula QM et $\mathrm{al}^{8}$ in Bangladesh observed hepatomegaly in $12.6 \%$ and splenomegaly in $17.4 \%$ of children with acute leukemia. Arya LS et al ${ }^{16}$ observed hepatosplenomegaly in 92\% and Kapoor G and Prabhash $\mathrm{K},{ }^{15}$ in $85 \%$ of acute leukemia cases. Both of these studies were conducted in India. In contrary,
Baka $\mathrm{M}$ et $\mathrm{al}^{17}$ in Greece found hepatosplenomegaly only in $23.8 \%$ of ALL cases. This could be due to the fact that their sample size was only 21 .

In this study most of the children (88.3\%) with acute lymphoblatic leukemia had total leukocyte count in the range of $10,000 / \mathrm{cmm}$ to $50,000 / \mathrm{cmm}$, which was a favorable prognostic factor ${ }^{6}$. Only $11.7 \%$ of children present with $\mathrm{WBC}>50,000 / \mathrm{cmm}$, which was a bad prognostic factor. It may be because most of our patient came from remote areas and presented late. Mannan et $\mathrm{al}^{14}$ in a study conducted in Bangladesh observed $>100000 / \mathrm{cmm}$ leukocytes count in $20 \%$ of children with ALL. Arya LS et al ${ }^{16}$ found leukocyte count >50000/ $\mathrm{cmm}$ in $32 \%$ of children with ALL. Less than $20,000 /$ $\mathrm{cmm}$ platelets count was observed in $40 \%$ of children with ALL in this study. However, thrombocytopenia was found in majority of the children. Platelet count $>100000 / \mathrm{cmm}$ was observed only in $25 \%$ of cases.

Majority of children with ALL (85\%) had hemoglobin level 7 to 11 gms and $15 \%$ of the cases had hemoglobin level was $<7$ grams. Blast cells were observed in majority of cases with acute lymphoblastic leukemia (78.3\%), atypical cells were present in (6.7\%) and blasts cells were absent in (15\%) of the cases in this study.

Among 300 patients followed, 84 (28\%) completed their treatment, and after 10 years of follow up without relapse were considered cured. ${ }^{18} 53(17.7 \%)$ are on maintenance chemotherapy. Due to financial and other reasons 91 (30.3\%) of our patients abandoned the treatment and could not be traced. 72 (24\%) patients have been reported dead as per our hospital documents.

Event free survival for more than 5 years from our study shows $28 \%$ (84 patients) which is lower than that reported from India $(70.87 \%)^{19}$

\section{Conclusion}

Acute leukemia is the most common childhood cancer and ALL constitute $>2 / 3^{\text {rd }}$ of acute leukemia cases. The common age group is 2-6 years. The common presentations are fever, hepatospleenomegaly, lymphadenopathy and echymosis. In about one third of cases, peripheral blood smear didn't show blast cells but bone marrow was positive for ALL.

Five years survival rate was $28 \%$ which is mainly due to lost to follow up and high mortality due to various factors. 


\section{Recommendation}

There is strong need to develop financial support system to take care of accommodation, transportation and treatment of the patient. We would like to recommend making bone marrow aspiration examination mandatory in all patients of clinically suspected ALL because only peripheral blood smear examination might not be conclusive.

Acknowledgements: The authors would like to thank all children, parents, staffs at oncology unit. Special thanks to Dr. Susan Bhattarai for his help.

Funding: Nil

Conflict of Interest: Nil

Permission from IRB:yes

\section{References}

1. Tubergen DG, Archie B. The leukemia. In, Robert M. Kliegman(ed). Nelson Text book of pediatrics, $17^{\text {th }}$ edition. Philadelphia, Elsevier, 2004:16941702.

2. Saha V, Eden T. An Odyssey in search of a cure: the evolution of treatment of childhood ALL in the United Kingdom. Indian J Pediatr 1993;60(4):52538.

3. Afiqul Islam, Tim Eden. Brief report on pediatric oncology in Bangladesh. South Asian J Cancer 2013;2:105-6.

4. Kamalakshi B, Anupama S Borker, et al. Survival of children with acute lymphoblastic leukemia using a uniform protocol over a 10 years period: results from a medical college hospital in southern India. Pediatr Blood Cancer 2010;55:861.

5. Karmacharya LL, Sah KP, Joshi P. Pediatric Oncology in Kanti Children Hospital: Challenges ahead. $\mathrm{KCH}$ Souvenir 2005; p57-59.

6. Margolin JF, Steuber CP, Poplack DG. Acute lymphoblastic leukemia. In, Pizzo PA, Poplack DG (ed). Principle and practice of pediatric oncology, $5^{\text {th }}$ edition. Philadelphia, Lippincort-Reven,1997:560.

7. Sitaresmi MN, Mostert S, Gundy CM, Ismail D, Veerman AJ. A medication diary-book for pediatric patients with acute lymphoblastic leukemia in Indonesia. Pediatr Blood Cancer 2013;60(10):15937.
8. Moula QM, Hossain A, Yunus EB, Mannan MA. Childhood leukaemia: A study of 93 cases. Bang J Child Health 1988;12:21-24.

9. Judith F.M, Philip S, David G.P. Acute Lymphoblastic Leukemia. In: Philip A., David G.P, editors. Principles and Practice of Pediatric Oncology. Philadelphia: Lippincott Williams and Wilkins;2006. p. 538-590.

10. Makimbetov EK. Childhood leukemia incidence in Kyrgyz Republic. Pediatr Blood Cancer 2004;43(4):453.

11. D'Costa GG, Siddiqui HM, Pradhan RM, et al. Pattern of leukemia : A ten- year incidence study of 242 cases. J Postgrad Med 1989;35:191-5.

12. Dabbous IA, Dbouk H, Sibai AM, Bahlawan L. Childhood acute lymphoblastic leukemia managed in tertiary care center in a developing country. Med Pediatr Oncol 2003;41(4):83-84.

13. David G, Archie B, Ritchey AK. Acute lymphobastic leukemia. In: Kliegman RM, Stanton ST BF, Geme III JW, Schor NF, Behrman RE, (ed). Nelson Textbook of Pediatrics. 19th ed. Philadelphia: Elsevier; 2011. p. 1732-1737.

14. Mannan MA, Islam A, Zamal CY, Gosh NK. Acute lymphoblastic leukemia. Med Pediatr Oncol 2003;41(4):286.

15. Kapoor G, Prabhash K. Childhood Acute lymphoblastic leukemia : Experience with a moderately aggressive protocol in a developing country. Pediatr Blood Cancer 2004;43(4):369.

16. Arya LS, Padmanjali KS, Srivastav A et al. Clinical feature and outcome of children with acute lymphoblastic leukemia treated with uniform regimen. Pediatr Blood Cancer 2004;43(4):369.

17. Baka M, Pourtsidis A, Dognis D, et al. Characteristics and outcome of children with high risk acute lymphoblastic leukemia. Pediatr Blood Cancer 2004;43(4): 369.

18. Pui CH, Cheng C, Leung W, Rai SN, Rivera GK, Sandlund JT, et al. Extended follow-up of longterm survivors of childhood acute lymphoblastic leukemia. N Engl J Med 2003;349(13):1299.

19. Jain V, Sachdeva A, Pruthi PK, Yadav SP, Gupta $\mathrm{S}$, Singh $\mathrm{N}$ et al. Outcome of treatment of acute lymphobastic leukemia in childhood with a single protocol - a ten year follow up. Pediatr Blood Cancer 2004;43:415. 